\title{
PENGARUH PSYCHOLOGICAL CAPITAL TERHADAP READINESS TO CHANGE \\ PADA KARYAWAN PENJAGA GARDU TOL DI JABODETABEK
}

\author{
Ahadian Almizan Gani' ${ }^{1)}$, Silverius Y. Soeharso'), Seta A. Wicaksana ${ }^{3)}$, Aisyah Pia \\ Asrunputri ${ }^{4)}$ \\ Fakultas Psikologi Universitas Pancasila \\ Email: ${ }^{1)}$ aalmizangani@gmail.com, ${ }^{2)}$ sonny.soeharso@gmail.com, \\ ${ }^{3)}$ seta.wicaksana@univpancasila.ac.id, ${ }^{4}$ aisyahpia@yahoo.com
}

\begin{abstract}
Abstrak
Pemerintah di Indonesia mulai membuat kebijakan untuk memberlakukan Gerakan Nasional Non Tunai (GNNT) yang telah diresmikan sejak tahun 2014 lalu dan gerakan ini dimulai dari penerapan pada transaksi di ruas jalan tol yang ada di Jabodetabek. Tujuan utama penelitian ini adalah untuk mengetahui pengaruh psychological capital terhadap readiness for change pada karyawan penjaga gardu tol di Jabodetabek. Penelitian ini menggunakan alat ukur Skala Readiness for Change untuk mengukur kesiapan individu dalam menghadapi perubahan organisasi dan Psychological Capital Questionnaire untuk mengukur tingkat psychological capital pada responden penelitian. Responden pada penelitian ini berjumlah 103 orang yang berstatus sebagai karyawan penjaga gardu tol di Jabodetabek. Hasil dari penelitian ini menunjukkan bahwa terdapat pengaruh yang signifikan dari psychological capital terhadap readiness for change dan resilience merupakan dimensi yang paling memberikan pengaruh secara signifikan dalam mempengaruhi readiness for change pada karyawan penjaga gardu tol di Jabodetabek.
\end{abstract}

Kata kunci: Readiness for change, psychological capital, karyawan penjaga gardu tol

\begin{abstract}
The government of Indonesia has started to create a policy to enact Gerakan Nasional NonTunai (GNNT) which was inaugurated since last 2014 and this movement started from the implementation of transaction at Jabodetabek toll road. The main purpose of this research is to evaluate the influence of psychological capital on readiness for change among toll gate guards in Jabodetabek. This research used Readiness for change scale to measure the individual readiness in facing organizational change and psychological capital questionnaire is used to measure the level of psychological capital among the respondent of the research. The respondent of this research focuses on 103 toll gate guards in Jabodetabek area. The result shows that there is a significant impact of psychological capital on readiness for change and resilience is the dimension that most significantly influences the readiness for change among the toll gate guards in Jabodetabek.
\end{abstract}

Key words: Readiness for change, psychological capital, toll gate guards 


\section{PENDAHULUAN}

Semakin dinamisnya perkembangan lingkungan, organisasi akan selalu dihadapkan dengan berbagai permasalahan yang membutuhkan adanya perubahan baik dalam segi strategi, budaya, struktur maupun proses yang ada (Armenakis, dkk., 1993). Untuk itu agar organisasi dapat terus mengikuti arus globalisasi maka organisasi perlu berubah sesuai kebutuhan dan tuntutan dari lingkungan sekitarnya (Fachruddin \& Mangundjaya, 2012). Hampir semua organisasi harus menyesuaikan dengan lingkungan yang multi-kultural, perubahan demografis dan perkembangan teknologi (Robbins \& Judge, 2013).

Perubahan adalah kata yang biasa digunakan oleh eksekutif perusahaan dalam menghadapi kemajuan dunia. Kompetisi global, metode manufaktur berbasis komputer dan komunikasi yang cepat sejak era Revolusi Industri memberi dampak yang cukup besar terhadap berbagai perusahaan dan organisasi dunia (Ivancevich dkk., 2014). Banyak perusahaan besar yang mampu untuk menghadapi tantangan perubahan, seperti Sony, McDonald's, Google dan Microsoft ataupun yang tidak mampu dalam menghadapi perubahan dan akhirnya berhenti seperti Aloha Airlines, Levitz Furniture dan Circuit City. (Ivancevich dkk., 2014).

Di Indonesia sendiri terdapat beberapa perusahaan yang mengalami perubahan seperti PT Pos Indonesia (Marketeers Editor, 2013), PT Kereta Api Indonesia (Ratya, 2017) dan yang kerap ramai belakangan waktu ini terjadi pada perusahaan-perusahaan pengelola jalan tol akibat dampak dari peraturan yang dibuat oleh BUJT untuk mengganti sistem transaksi menjadi non tunai dalam rangka meningkatkan efisiensi perekonomian masyarakat Indonesia. Hal ini dikarenakan Gubernur dari Bank Indonesia (BI), Agus D.W. Martowardojo, meresmikan program "Gerakan Nasional Non Tunai (GNNT)" yang telah telah dilaksanakan sejak tahun 2014 lalu (Departemen Komunikasi, 2014).

Dengan adanya gerakan GNNT diharapkan agar masyarakat menyadari bahwa melakukan transaksi non tunai merupakan cara yang lebih praktis dan efisien dibandingkan dengan transaksi tunai, hal ini dikarenakan selain prosesnya yang lebih cepat transaksi non tunai dapat mencatat transaksi serta pengawasannya lebih mudah sehingga dapat mencegah resiko salah perhitungan ataupun transaksi ilegal (Jakarta Smart City, 2017). Untuk saat ini sistem transaksi non tunai sudah diterapkan pada transportasi umum seperti Bus Transjakarta dan Kereta Listrik Commuterline, nantinya transportasi umum yang baru yaitu mass rapid transit (MRT) dan light rail transit (LRT) akan langsung menggunakan sistem transaksi non tunai (Carina, 2017).

Untuk mendukung program transaksi non

tunai, Badan Usaha Jalan Tol (BUJT) memutuskan bahwa seluruh ruas tol di Jakarta sudah tidak melayani transaksi tunai lagi pertanggal 31 Oktober 2017 sehingga masyarakat dihimbau untuk beralih ke transaksi non tunai. Menurut Dwimawan Heru selaku AVP Corporate Communication dari PT Jasa Marga, penerapan transaksi non tunai di jalan tol ini diharapkan dapat mengurangi kemacetan akibat dari mengantri transaksi tunai di gerbang tol. Ia mengatakan bahwa penerapan sistem ini dapat memangkas separuh waktu dari transaksi tunai (Prabowo, 2017).

Dengan diterapkannya sistem ini, secara otomatis transaksi di jalan tol akan menggunakan mesin secara keseluruhan. Sebagai Badan Usaha Milik Negara (BUMN) PT Jasa Marga mengatakan tidak akan melakukan pemutusan hubungan kerja (PHK) pada para penjaga pintu tol. Vice President Operation Management dari Jasa Marga, Raddy R. Lukman, mengatakan bahwa para penjaga tol sebanyak 1300 karyawan ini akan dialihfungsikan pekerjaannya sehingga tidak ada tindakan PHK (Prabowo, 2017).

Selain Jasa Marga, salah satu BUJT swasta yang mengelola jalan tol Jakarta-Merak juga memastikan untuk tidak melakukan PHK kepada para 500 karyawan penjaga tol-nya. Hal ini disampaikan oleh Kepala Divisi Hukum dan Humas dari perusahaan tersebut (Joniansyah, 2017) yang menyampaikan bahwa 500 karyawan penjaga tol dari perusahaan tersebut akan dialihfungsikan sebagai tenaga pengawas untuk 
mesin transaksi non tunai tersebut. BUJT Swasta ini memiliki 10 gerbang tol sepanjang wilayah Banten-Jakarta yang terdiri dari 87 gardu. Kepala Divisi Operasi dari perusahaan tersebut mengatakan bahwa pengguna transaksi non tunai telah meningkat sebesar $66 \%$ per-tanggal 4 Oktober ini. mereka sendiri memiliki target pada tanggal 12 Oktober sudah $100 \%$ menggunakan transaksi non tunai (Joniansyah, 2017).

Perubahan sistem menjadi non tunai pastinya akan lebih banyak menggunakan mesin dibandingkan tenaga karyawan dari perusahaan itu sendiri. Hal ini dapat berdampak terhadap bergesernya tugas karyawan. Jika sebelumnya pekerjaan karyawan adalah melakukan proses transaksi tunai, kini mereka dialih-fungsikan ke peran yang lain. Adanya perubahan pada organisasi memberikan dampak terhadap lingkungan kerja, kesejahteraan karyawan, motivasi dan performa karyawan (Heuvel dkk., 2010).

Perubahan karena teknologi seperti permasalahan di atas dapat menjadi salah satu faktor pemicu stres pada karyawan (Gibson dkk., 2012). Karyawan juga memiliki ketakutan jika perubahan terjadi pada perusahaannya maka akan berdampak negatif terhadap pekerjaannya ataupun pihak manajemen tidak berkomitmen untuk mendukung perubahan tersebut (Ivancevich, Konopaske \& Matteson, 2014). Oleh karena itu karyawan harus siap dalam menghadapi perubahan yang terjadi di organisasinya.

Dalam mengatasi hal tersebut, perusahaan dapat melakukan perencanaan untuk melakukan perubahan secara bertahap dengan metode perencanaan perubahan organisasi (Cummings \& Worley, 2009). Menurut Meaney dan Pung (2008) untuk melakukan perencanaan perubahan organisasi perlu dilaksanakan secara benar karena dari survei yang telah mereka lakukan terhadap 3199 eksekutif perusahaan menemukan bahwa hanya sepertiga respondennya yang mengatakan perusahaannya berhasil mencapai tahap perubahan yang sebenarnya. Leonard, Lewis, Freedman dan Passmore (2013) mengatakan duapertiga dari proyek perubahan perusahaan biasanya berakhir gagal.

Peluang suatu organisasi gagal dalam melakukan perubahan pada organisasinya sebesar
70\% (Tappin, 2014). Gagalnya melakukan implementasi perubahan ini biasanya disebabkan karena ketidakmampuan individu dalam mempersiapkan diri untuk melakukan perubahan yang telah direncanakan (Choi \& Rouna, 2010). Hal ini didukung dengan pernyataan Fuegen dan Brehm (dalam Knowles \& Linn, 2004) yang mengatakan sejatinya individu memang tidak tahan dengan adanya perubahan.

Salah satu hal yang memiliki peran penting dalam perubahan organisasi adalah individu yang menjadi bagian dari organisasi tersebut (Robbins, 2013). Untuk itu individu perlu siap dengan perubahan yang terjadi di organisasinya (Armenakis dkk., 1993). Kesiapan menghadapi perubahan (readiness for change) dapat didefinisikan sebagai bentuk pemahaman individu mengenai perubahan yang dibutuhkan oleh organisasinya, individu tersebut yakin bahwa dirinya dapat mengimplementasikan perubahan yang telah direncanakan/diusulkan serta mempercayai bahwa perubahan ini dapat memberikan dampak positif, baik untuk dirinya sendiri maupun organisasi (Armenakis dkk., 1993; Jones, dkk., 2005; Holt dkk., 2007).

Terdapat beberapa faktor yang mempengaruhi individu untuk memiliki kesiapan dalam menghadapi perubahan pada organisasinya (Cunningham dkk., 2002) yaitu dimensi pekerjaan aktif-pasif dan dukungan sosial. Karasek dan Theorell (dalam Cunningham dkk., 2002) mengatakan bahwa pekerjaan dengan tuntutan dan pengambilan keputusan yang rendah didefinisikan sebagai dimensi pasif sedangkan dimensi aktif meningkatkan kesempatan karyawan untuk belajar dan berkontribusi terhadap tekanan yang didapatkan sehingga dapat meningkatkan motivasi dan membentuk pola perilaku yang baru.

Kemudian, dukungan sosial hadir sebagai bentuk interaksi individu dengan pekerjaan aktif untuk memperkirakan bagaimana individu dapat menyesuaikan diri dengan tempat kerja. Selain itu dari berbagai penelitian sebelumnya terdapat beberapa faktor yang memiliki pengaruh terhadap readiness for change diantaranya, budaya organisasi, operating climate, perceived management support, perceived impact of change, komitmen organisasi dan psychological capital (McNabb \& Sepic dalam Hanpachern, 
dkk., 1998; Vakola, 2014; Ming-Chu \& MengHsiu, 2015; Jabbarian \& Chegini, 2016; Suwaryo, dkk., 2016; Kirrane, dkk., 2016).

Untuk menghadapi perubahan organisasi seperti yang dipaparkan sebelumnya individu perlu untuk mempersiapkan sumber daya psikologis (psychological resource) pada diri mereka sendiri dalam menghadapi perubahan tersebut (Kirrane, 2016). Menurut Luthans, Avey, Avolio dan Peterson (2010) psychological capital merupakan sumber daya psikologis yang tidak terbatas pada diri manusia dan dapat ditingkatkan serta dikembangkan oleh individu itu sendiri untuk mencapai kesuksesan dalam meraih tujuan yang dimilikinya.

Menurut Avey, Wernsing dan Luthans (2008) psychological capital menjadi hal yang sangat penting dalam menghadapi kondisikondisi kritis yang mungkin saja akan terjadi pada saat proses perubahan di organisasi sedang berlangsung. Pernyataan tersebut mendukung apa yang ditemukan oleh Ming-Chu dan Meng-Hsiu (2015) yaitu psychological capital memiliki hubungan dengan kesiapan karyawan dalam menghadapi perubahan di organisasinya. Penelitian ini dilakukan terhadap 288 karyawan di perusahaan manufaktur elektronik yang ada di Taiwan.

Kemudian dari Jabbarian dan Chegini (2016) menemukan bahwa psychological capital memiliki pengaruh yang positif terhadap kesiapan individu dalam menghadapi perubahan. Hasil dari penelitian tersebut menunjukkan apabila tingkat psychological capital tinggi pada diri indvidu, maka akan berdampak pada kesiapan individu yang meningkat juga dalam menghadapi perubahan organisasi. Penelitian ini dilakukan pada 254 orang pegawai kepemerintahan di Provinsi Guilan, Iran. Sehingga pernyataan dan temuan yang telah dijelaskan sebelumnya dapat menunjukkan bahwa psychological capital berkaitan dengan kesiapan individu dalam menghadapi perubahan di organisasi.

Avey, Youssef dan Luthans (2009) mengatakan bahwa setiap dimensi yang ada pada psychological capital ini saling mempengaruhi sehingga konstruk pada variabel psychological capital ini akan lebih terlihat apabila dilakukan pengukuran secara satu kesatuan psychological capital. Tetapi dari beberapa penelitian sebelumnya menunjukkan bahwa tiap komponen dari psychological capital memiliki hubungannya masing-masing dengan variabel penelitian lainnya seperti job satisfaction dan innovative behavior (Yan \& Lingli, 2011; Kaplan \& Biçkes, 2012; Ratnaningsih, dkk. 2016).

Berdasarkan dari penjelasan yang telah dipaparkan di atas, peneliti ingin melihat pengaruh dari faktor psychological capital terhadap readiness for change pada individu tetapi dengan dua teknik analisis yang berbeda. Sehingga dalam penelitian ini akan mencari tahu pengaruh psychological capital secara keseluruhan dan tiap dimensi dari psychological capital terhadap readiness for change pada individu, yang mana dalam penelitian ini adalah karyawan penjaga gardu tol di Jabodetabek.

\section{RUMUSAN MASALAH}

Berdasarkan pada pendahuluan di atas, maka masalah dalam penelitian ini dapat dirumuskan yakni sebagai berikut:

1. Apakah terdapat pengaruh psychological capital terhadap readiness for change pada karyawan penjaga gardu tol di Jabodetabek.

2. Apakah terdapat pengaruh efficacy terhadap readiness for change pada karyawan penjaga gardu tol di Jabodetabek.

3. Apakah terdapat pengaruh optimism terhadap readiness for change pada karyawan penjaga gardu tol di Jabodetabek.

4. Apakah terdapat pengaruh hope terhadap readiness for change pada karyawan penjaga gardu tol di Jabodetabek.

5. Apakah terdapat pengaruh resilience terhadap readiness for change pada karyawan penjaga gardu tol di Jabodetabek.

\section{TINJAUAN PUSTAKA}

\section{Readiness for Change}

Didefinisikan sebagai kesiapan secara psikologis serta fisik, bentuk pemahaman 
individu mengenai perubahan yang dibutuhkan oleh organisasinya, keyakinan individu untuk dapat mengimplementasikan perubahan yang direncanakan/diusulkan dan mempercayai bahwa perubahan ini dapat memberikan dampak positif, baik untuk dirinya sendiri maupun organisasi (Armenakis dkk., 1993; Hanpachern dkk., 1998; Jones dkk., 2005; Holt dkk., 2007).

Terdapat tiga dimensi mengenai kesiapan individu dalam menghadapi perubahan diantaranya adalah promoting, participating dan resisting (Hanpanchern dkk., 1998). Promoting adalah kondisi individu dimana ia mendorong adanya perubahan pada organisasinya. Participating merupakan kondisi individu dimana ia berpartisipasi dalam menjalani proses perubahan. Sedangkan resisting adalah kondisi saat individu tidak mendukung adanya perubahan pada organisasinya.

\section{Psychological Capital}

Adalah kondisi dimana individu memiliki harapan, efikasi diri, resiliensi dan optimisme dalam menjalani produktifitas untuk mencapai suatu kesuksesan sehingga individu tersebut dapat memahami siapa dirinya dan apa yang diinginkannya (Luthans \& Youssef, 2004; Luthans dkk., 2007). Menurut Luthans dkk. (2007) psychological capital merupakan suatu konstruk yang khusus dan berbeda dengan konstruk lain seperti character strengths and virtues (CSVs) dari Peterson dan Seligman ataupun dimensi dari Big Five personality traits karena psychological capital sebatas state-like, yaitu perilaku dapat dikembangkan dan dipelajari lebih lanjut lagi. Sedangkan konstruk seperti CSVs dan Big Five personality traits tergolong sebagai trait-like yang mana konstruk ini cenderung stabil dan sulit berubah karena trait/sifat cenderung menetap dan menjadi karakteristik individu.

Psychological capital terdiri dari empat dimensi yaitu efficacy, optimism, hope dan resilience (Luthans dkk., 2004). Efficacy adalah bentuk dari kepercayaan mengenai kemampuan diri dalam mengerahkan motivasi, kemampuan kognitif dan tindakan yang diperlukan sehingga individu mampu melaksanakan tugas dengan baik dan berhasil (Stajkovic \& Luthans, 1998; Maddux, 2000). Optimism adalah kondisi dimana individu memiliki keinginan dan harapan terhadap suatu peristiwa/kejadian dengan positif di masa depan serta sebagai gaya dan cara yang biasa dilakukan individu dalam menjelaskan mengenai kejadian dalam hidup mereka (Luthans dkk., 2007; Levene, 2015).

Hope adalah keadaan motivasi individu yang positif dan didasari dengan energi untuk mencapai tujuan dan berhasil melakukan perencanaan untuk mencapai tujuannya tersebut, sebagai cara individu dalam bergerak melakukan sesuatu untuk mendekati apa yang mereka inginkan seperti arah menuju tujuan yang telah ditetapkan oleh dirinya sendiri serta gagasan individu bahwa mereka dapat memiliki pandangan yang positif terhadap hasil di masa depan dari usaha yang mereka lakukan (Snyder, 2002; Avey dkk., 2010).

Resilience adalah kemampuan individu untuk bangkit kembali dari keterpurukan ketika individu menghadapi kekecewaan akan hasil yang didapat tidak sesuai ataupun kegagalan yang dialaminya dan beradaptasi dengan situasi tersebut serta membutuhkan kemampuan individu untuk mengelola trauma yang diakibatkan dari kegagalan atau pengalaman tidak baik tersebut sebagai sumber stres-nya (Luthans, 2002; Windle, 2011).

\section{METODE PENELITIAN}

\section{Subjek}

Dalam penelitian ini, sebanyak 103 karyawan penjaga gardu tol yang tersebar di Jabodetabek. Subjek terdiri dari 53 laki-laki $(51.5 \%)$ dan 50 perempuan $(48.5 \%)$, berusia dari 18-47 tahun. Rata-rata pendidikan terakhir dari subjek adalah SMA (55.3\%) dan S1 (32\%). Lama bekerja subjek mulai dari <1-24 tahun.

\section{Instrumen Penelitian}

Alat ukur yang digunakan dalam penelitian ini terdiri dari 2 bagian. (1) alat ukur readiness for change (12 item) dari Nugraheni (2012) yang diadaptasikan dari alat ukur Hanpachern (1997), dengan nilai item reliability 0.92 dan nilai alpha cronbach 0.68 ; (2) alat ukur psychological capital questionnaire (24 item) dari Sapyaprapa dkk. (2013) yang diadaptasi dari 
Luthans dkk. (2007), dengan nilai alpha cronbach 0.88 , dan nilai item reliability 0.79 .

\section{Teknik Olah Data}

Pada penelitian ini akan dilakukan dua teknik olah statistik untuk menguji variabel bebas secara keseluruhan dan per-dimensi terhadap variabel terikat. Analisis data yang digunakan dalam penelitian ini adalah uji asumsi klasik dengan uji normalitas,, sedangkan uji hipotesis dalam penelitian ini menggunakan regresi linear sederhana dan regresi linear berganda.

\section{Hipotesis Penelitian}

Hipotesis dari penelitian ini adalah terdapat pengaruh psychological capital terhadap readiness for change pada karyawan penjaga gardu tol di Jabodetabek $\left(\mathrm{Ha}_{1}\right)$; terdapat pengaruh efficacy terhadap readiness for change pada karyawan penjaga gardu tol di Jabodetabek $\left(\mathrm{Ha}_{2}\right)$; terdapat pengaruh optimism terhadap readiness for change pada karyawan penjaga gardu tol di Jabodetabek ( $\left.\mathrm{Ha}_{3}\right)$; terdapat pengaruh hope terhadap readiness for change pada karyawan penjaga gardu tol di Jabodetabek ( $\left.\mathrm{Ha}_{4}\right)$; terdapat pengaruh resilience terhadap readiness for change pada karyawan penjaga gardu tol di Jabodetabek (Ha5).

\section{HASIL DAN PEMBAHASAN}

\section{Hasil}

Berdasarkan norma kategorisasi data hasil penelitian, diketahui bahwa readiness for change pada karyawan penjaga gardu tol di Jabodetabel paling banyak berada di rentang sedang yaitu sebanyak 55 orang (55\%). Lalu, untuk gambaran psychological capital paling banyak berada pada rentang kategori sedang yaitu 51 orang (49.5\%). Sebelum melakukan uji hipotesis, peneliti melakukan uji asumsi klasik terlebih dahulu dengan melakukan uji normalitas.

\section{Uji Normalitas}

Uji normalitas dilakukan dengan One Sample Kolmogorov-Smirnov, menunjukkan bahwa distribusi data penelitian bersifat normal dengan nilai $\mathrm{p}=0.927(\mathrm{p}>0.05)$.

\section{Uji Hipotesis}

Hasil analisis regresi linear sederhana pada psychological capital terhadap readiness for change memperoleh nilai $\mathrm{R}$ Square sebesar 0,625 . Artinya $62.5 \%$ variabel kesiapan individu untuk berubah dipengaruhi oleh psychological capital sedangkan $37.5 \%$ dipengaruhi oleh variabel-variabel lain diluar penelitian.

Hasil analisis regresi linear berganda pada dimensi psychological capital (efficacy, optimism, hope dan resilience memperoleh $\mathrm{R}$ Square sebesar 0.643 . Artinya $64.3 \%$ variabel kesiapan individu untuk berubah dipengaruhi oleh dimensi dari psychological capital sedangkan $35.7 \%$ dipengaruhi oleh variabelvariabel lain diluar penelitian.

\section{Uji F}

Berdasarkan hasil pengujian, signifikansi $\mathrm{F}$ dan uji model regresi adalah 0,000 dan nilai level of significance sebesar 0,05. Nilai signifikansi lebih kecil dari 0,05 tersebut menandakan bahwa tiap variabel bebas yang merupakan dimensi dari psychological capital memiliki pengaruh yang signifikan terhadap readiness for change secara simultan.

\section{Uji $t$}

Hasil yang diperoleh yaitu, nilai koefesien regresi psychological capital adalah 0359 dengan t-value 12.966 (sig. 0.000), artinya psychological capital memberikan pengaruh positif yang signifikan terhadap readiness for change. Sehingga, semakin tinggi psychological capital maka semakin tinggi pula readiness for change pada responden dan sebaliknya. Dari hasil ini dapat dikatakan bahwa $\mathrm{Ha}_{1}$ pada penelitian ini diterima.

Sedangkan, hasil yang diperoleh pada nilai koefesien regresi dari dimensi psychological capital adalah 0.258 (efficacy), 0.405 (optimism), 0.070 (hope) dan 0.765 (resilience). Dari nilai koefisien tersebut hanya resilience yang memiliki nilai $\mathrm{P}<0.05$ yaitu sebesar 0.000 , sehingga koefisien regresi dari resilience memiliki pengaruh yang signifikan sebesar 0.765. Dapat diartikan bahwa resilience merupakan dimensi yang mempengaruhi readiness for change pada responden secara positif dan signifikan. Artinya, semakin tinggi resilience maka semakin tinggi 
pula readiness for change pada responden. Dari hasil ini dapat dikatakan bahwa Has pada penelitian ini diterima.

\section{Pembahasan}

Hasil pada penelitian ini menunjukkan bahwa psychological capital memiliki pengaruh yang signifikan terhadap readiness for change pada karyawan penjaga gardu tol di Jabodetabek. Hal ini didukung oleh penelitian sebelumnya dari Ming-Chu dan Meng-Hsiu (2015) yang mengatakan bahwa terdapat hubungan yang signifikan dari psychological capital dengan readiness to change yang mereka teliti pada karyawan perusahaan manufaktur elektronik di Taiwan.

Hasil dari penelitian ini juga semakin diperkuat dari penelitian Jabbarian dan Chegini (2016) yang mengemukakan bahwa psychological capital memiliki pengaruh yang positif terhadap readiness for change. Penelitian yang mereka lakukan menggunakan subjek yang berbeda yaitu pada pegawai kepemerintahan Provinsi Guilan, Iran. Sehingga dapat dikatakan hasil penelitian ini sejalan dengan apa yang dikatakan oleh Kirrane (2016) yang mengatakan bahwa individu perlu mempersiapkan sumber daya psikologisnya berupa psychological capital (Luthans, dkk., 2010) untuk meningkatkan readiness for change terhadap perubahan organisasi yang akan ataupun sedang dijalankan di organisasi.

Selanjutnya dari hasil penelitian ini jika psychological capital tidak diukur secara satu kesatuan, hasilnya menunjukkan bahwa dimensi resilience merupakan satu-satunya dimensi yang memberikan pengaruh secara signifikan terhadap readiness for change pada responden. Hal ini bisa terjadi karena berdasarkan hasil penelitian Wanberg dan Banas (2000) mengatakan bahwa terdapat hubungan yang tinggi antara resilience dengan penerimaan individu terhadap perubahan organisasi, sehingga peneliti berasumsi bahwa ada kemungkinan hal tersebut yang memberikan dampak kepada resilience dan memiliki pengaruh terhadap kesiapan individu dalam menghadapi perubahan organisasi sebelum karyawan dapat menerima perubahan tersebut.

Resilience sendiri didefinisikan sebagai kemampuan individu untuk bangkit kembali dari keterpurukan yang terjadi ketika individu menghadapi kekecewaan akan hasil yang didapat tidak sesuai ataupun kegagalan yang dialaminya dan beradaptasi dengan situasi tersebut (Luthans, 2002). Menurut Reivich dan Shatte (dalam Levene, 2015) resilience berfungsi untuk mengatasi rintangan permasalahan dalam kehidupan, mengarahkan individu untuk menyelesaikan masalahnya, bangkit kembali dari keterpurukan diri dan membantu individu menemukan makna dari permasalahan yang dihadapi agar dapat terbuka kembali dengan pengalaman yang baru dan berkembang kembali.

Pada penelitian ini juga menunjukkan bahwa efficacy tidak memberikan pengaruh yang signifikan terhadap readiness for change. Hal ini tidak sejalan dengan penelitian dari Angkawijaya, Arista dan Dewi (2018) yang menyatakan bahwa efficacy memiliki pengaruh terhadap readiness for change. Peneliti mengasumsikan perbedaan hasil tersebut dikarenakan adanya perbedaan alat ukur yang digunakan dalam mengukur tingkat resilience pada karyawan. Pada penelitian ini menggunakan psychological capital questionnaire dari Sapyaprapa, Tuicomepee dan Watakakosol (2013) yang diadaptasi dari kuesioner milik Luthans tahun 2004 dan kemudian peneliti mengukur dari dimensi efficacy. Sedangkan pada penelitian Angkawijaya, Arista dan Dewi (2018) menggunakan alat ukur general self efficacy scale dari Bandura tahun 2001.

Untuk dimensi hope dan optimism, berdasarkan hasil penelitian ini menunjukkan bahwa kedua dimensi tersebut tidak memberikan pengaruh yang signifikan terhadap readiness for change pada karyawan. Peneliti mengindikasikan hal ini terjadi dikarenakan saat organisasi mengalami proses perubahan maka karyawan berada di dalam kondisi dimana segala kemungkinan dapat terjadi sehingga karyawan tidak memiliki banyak ekspektasi mengenai bagaimana kondisi organisasi dan dirinya di masa mendatang. Maka dari itu pada penelitian ini hanya resilience yang memberikan pengaruh terhadap kesiapan karyawan menghadapi perubahan organisasi.

Sehingga dapat disimpulkan dengan adanya perubahan organisasi akibat dari perkembangan teknologi seperti yang dialami 
Badan Usaha Jalan Tol (BUJT) saat ini, karyawan penjaga gardu tol memiliki tingkat psychological capital dan readiness for change yang sedang (berdasarkan tabel 4.6 dan tabel 4.7). Dimensi yang paling mempengaruhi kesiapan mereka adalah resilience sehingga mereka mampu menghadapi adanya pergeseran/penggantian tugas yang mereka alami seperti sekarang.

Untuk meningkatkan tingkat dari psychological capital ini, perusahaan dapat membuat pelatihan sesuai dengan kebutuhan untuk para karyawan. Hal ini dikarenakan psychological capital merupakan konstruk yang state-like, yaitu perilaku dapat dikembangkan serta dipelajari lebih lanjut lagi oleh individu (Luthans, dkk., 2007). Menurut Luthans, Avolio, Avey dan Norman (2010) psychological capital dapat dikembangkan pada diri individu dengan diadakannya pelatihan (training).

Hasil penelitian eksperimen Luthans, Avey dan Patera (2008) menunjukkan dengan diadakannya program web-based training dapat meningkatkan psychological capital pada 187 karyawan dari kelompok yang diberi intervensi. Melakukan inisiatif seperti ini dengan memperkenankan waktu, ruang dan aktivitas untuk mengembangkan tingkat psychological capital dapat meningkatkan readiness to change pada karyawan sehingga mendorong karyawan untuk dapat beradaptasi secara efektif pada perubahan yang sedang dijalankan oleh organisasi (Kirrane, dkk., 2016). Menurut Levene (2015) untuk memunculkan keinginan karyawan agar mau terlibat dengan perubahan dapat dilakukan dengan meningkatkan tiap elemen yang ada pada psychological capital.

Selain itu, menurut Luthans (dalam Lewis, 2011) untuk meningkatkan resilience pada individu dapat dilakukan dengan tiga cara yaitu dengan mengakumulasikan modal kemampuan individu dari pengalamannya, membantu individu untuk belajar dari rintangan yang dihadapinya sehingga mereka akan mengalami pertumbuhan diri kembali pasca trauma (posttraumatic growth) dan menyadarkan individu bahwa keadaan mental dan fisik mereka dapat mempengaruhi tingkat ketahanan mereka sehingga individu diharapkan mampu untuk mengelola keadaan tersebut.
Dalam era perkembangan teknologi seperti saat ini banyak sekali kemungkinan perubahan yang terjadi akibat dampak dari teknologi. Survey dari Ernst Young (2013) mengatakan bahwa pertumbuhan ekonomi perusahaan di dunia diperkirakan akan bertambah sebesar 57\% di tahun 2015. Kemudian dalam survey terbarunya Ernst Young (2017) menjelaskan bahwa nantinya model bisnis berbasis digital akan memimpin agenda strategis di tahun 2020.

Dampak dari perkembangan teknologi pastinya akan berpengaruh terhadap banyak perusahaan akibat perkembangan teknologi digital yang mana secara tidak langsung setiap individu yang merupakan bagian dari suatu perusahaan mau tidak mau harus bisa bersiap dalam menghadapi perubahan di perusahaannya, sehingga perusahaan perlu mempertahankan dan mencari individu yang mampu bertahan dan menyesuaikan diri terhadap perubahan organisasi dengan cepat. Oleh karena itu penelitian yang mengkaji mengenai readiness for change sangat diperlukan untuk menghadapi era saat ini dimana perkembangan teknologi dan informasi dapat terjadi dengan sangat cepat.

\section{KESIMPULAN DAN SARAN}

\section{Kesimpulan}

Berdasarkan dari hasil uji hipotesis pada penelitian ini maka dapat disimpulkan bahwa "terdapat pengaruh yang signifikan dari psychological capital terhadap readiness for change pada karyawan penjaga gardu tol di Jabodetabek". Kemudian berdasarkan hasil signifikansi dari tiap koefisien regresi pada dimensi psychological capital didapatkan bahwa hanya satu variabel dari psychological capital, yaitu resilience yang memiliki pengaruh secara signifikan terhadap readiness for change.

Sehingga dari kesimpulan tersebut dapat dikatakan bahwa $\mathrm{Ha}_{1}$ dan $\mathrm{Ha}_{5}$ dari penelitian ini diterima, yaitu "terdapat pengaruh yang signifikan dari psychological capital terhadap readiness for change pada karyawan penjaga gardu tol di Jabodetabek" dan "terdapat pengaruh yang signifikan dari resilience terhadap readiness for change pada karyawan penjaga gardu tol di Jabodetabek". 


\section{Saran}

Peneliti mengajukan beberapa saran baik metodologis maupun praktis yang mungkin bisa diterapkan untuk penelitian berikutnya. Berikut ini merupakan saran yang akan dipaparkan oleh peneliti.

\section{Saran Metodologis}

Setelah melakukan dan mengkaji kembali penelitian ini, peneliti menyadari bahwa penelitian ini masih memiliki kekurangan. Oleh karena itu bagian ini akan memaparkan mengenai saran metodologis yaitu:

1. Penelitian ini akan lebih kaya apabila penelitian selanjutnya menggunakan faktor lain yang bersifat eksternal juga sehingga akan ada perbandingan hasil antara faktor internal dari individu dan faktor eksternal.

2. Untuk penelitian berikutnya akan lebih kaya hasilnya apabila penelitian seperti ini melakukan perbandingan antara perusahaan swasta dengan instansi pemerintah untuk melihat apakah ada perbedaan kesiapan di antara dua jenis perusahaan/instansi tersebut.

\section{Saran Praktis}

Berikut ini merupakan saran praktis yang bisa diterapkan dari penelitian yaitu:

Untuk perusahaan,

1. Saran untuk perusahaan agar dapat membuat pelatihan sesuai dengan kebutuhan karyawan dalam menghadapi perubahan organisasi untuk meningkatkan tingkat psychological capital pada karyawan, sehingga kesiapan mereka dalam menghadapi perubahan akan meningkat juga serta diiringi dengan penerimaan mereka terhadap perubahan yang telah direncanakan oleh organisasi untuk diimplementasikan pada karyawan.

2. Saran untuk perusahaan agar dapat memberikan informasi mengenai perubahan yang sedang terjadi sangat cepat di era digitalisasi seperti saat ini.

3. Perusahaan dapat menciptakan iklim kerja yang kondusif untuk mendorong karyawan agar dapat menghadapi perubahan pada organisasi dengan baik.

Untuk indvidu,
1. Perlu adanya kemauan untuk menghadapi perubahan yang terjadi selama perubahan tersebut memberi manfaat baik untuk karyawan maupun organisasi.

\section{UCAPAN TERIMA KASIH}

Terima kasih para penulis ucapkan kepada keluarga serta narasumber penelitian. Tanpa dukungan mereka penelitian ini tidak dapat berjalan dengan baik.

\section{DAFTAR PUSTAKA}

Angkawijaya, Y. F., Arista, P. D., \& Dewi, D. A. 2018. Berubah, siapa takut? Pengaruh efikasi diri terhadap kesiapan untuk berubah pada karyawan di PT TP Tangerang. Jurnal Muara Ilmu Sosial, Humaniora, dan Seni, 1(2).

Armenakis, A. A., \& Bedeian, A. G. 1999. Organizational change: A review of theory and research in the 1990s. Journal of Management, 25(3), 293-315.

Armenakis, A. A., $\quad$ Harris, S. G., \& Mossholder, K. W. 1993. Creating readiness for organizational change. Human Relations, 46(6).

Armenakis, A. A., Jimmieson, N. L., \& Rafferty, A. E. 2013. Change readiness: a multilevel review. Journal of Management, 39(1), 110-135.

Avey, J. B., Luthans, F., Smith, R. M., \& Palmer, N. F. 2010. Impact of positive psychological capital on employee wellbeing over time. Journal of occupational health psychology, 15(1), 17.

Avey, J. B., Wernsing, T. S., \& Luthans, F. 2008. Can positive employees help positive organizational change? Impact of psychological capital and emotions on relevant attitudes and behaviors. The Journal of Applied Behavioral Science, 44(1), 48-70.

Azwar, S. 1999. Penyusunan skala psikologi. Yogyakarta: Pustaka Pelajar.

Bank Indonesia mencanangkan gerakan nasional non tunai - Bank sentral Republik Indonesia (No. 16/58 /DKom). 2014. Retrieved from Departemen 
Komunikasi

website:

http://www.bi.go.id/id/ruang-

media/siaran-

pers/Pages/sp_165814.aspx

Boone, W. J., Staver, R. J., \& Yale, S. M. 2014. Rasch Analysis in the Human Sciences. London: Springer.

Carina, J. 2017, September 6. Pemerintah ingin transportasi umum di Jakarta gunakan sistem non-tunai - Kompas.com. Retrieved October 20, 2017, from http://megapolitan.kompas.com/read/20 17/09/06/12591841/pemerintah-ingintransportasi-umum-di-jakarta-gunakansistem-non-tunai

Carver, C. S., Scheier, M. F., \& Segerstrom, S. C. 2010. Optimism. Clinical psychology review, 30(7), 879-889.

Chaplin, J. P. 2006. Kamus lengkap psikologi. Jakarta, Indonesia: PT RajaGrafindo Persada.

Choi, M., \& Ruona, W. E. 2010. Individual readiness for organizational change and its implications for human resource and organization development. Human Resource Development Review, 10(1), 46-73.

Choi, M., \& Ruona, W. E. 2013. Individual readiness for organizational change. The Wiley-Blackwell Handbook of the Psychology of Leadership, Change, and Organizational Development, 331-345.

Colman, A. M. 2015. A dictionary of psychology (4th ed.). Oxford, NY: Oxford University Press.

Cummings, T. G., \& \& Worley, C. G. 2009. Organization development and change (9th ed.). Mason, OH: SouthWestern College Pub.

Cunningham, C. E.,

Woodward, C. A., Shannon, H. S., $\quad$ MacIntosh, J., Lendrum, B., Rosenbloom, D., \& Brown, J. 2002. Readiness for organizational change: A longitudinal study of workplace, psychological and behavioural correlates. Journal of Occupational and Organizational Psychology, 75(4), 377-392.

Ernst Young. 2013. Digital agility now. Retrieved

from http://www.ey.com/gl/en/industries/tech nology/digital-agility-now

Ernst Young. 2017. EY - Digital transformation for 2020 and beyond. Retrieved from http://www.ey.com/gl/en/industries/telec ommunications/ey-digitaltransformation-for-2020-and-beyond

Fachruddin, D. F., \& Mangundjaya, W. H. 2012. The impact of workplace well-being and psychological capital, to the individual readiness for change. Proceedings 4th Asian Psychological Association, Jakarta, 5-7 July, 2012.

Feist, J., \& Feist, G. J. 2010. Teori kepribadian (7th ed.). Jakarta, Indonesia: Salemba Humanika.

Gibson, J. L., Ivancevich, J. M., Donnelly, Jr., J. H., \& Konopaske, R. 2012. Organizations: behavior, structure, processes (14th ed.). New York, NY: McGraw-Hill Irwin.

Hanpachern, C., Morgan, G. A., \& Griego, O. V. 1998. An extension of the theory of margin: A framework for assessing readiness for change. Human Resource Development Quarterly, 9(4), 339-350.

Heuvel, M., Demerouti, E., Bakker, A. B., \& Schaufeli, W. B. 2010. Personal resources and work engagement in the face of change. Contemporary Occupational Health Psychology, 1, 124-150.

Holt, D., Feild, H., Harris, S., \& Armenakis, A. 2007. Readiness for organizational change. The Journal of Applied Behavioral Science, 43(2), 232.

Isabella, L. A. 1990. Evolving interpretations as a change unfolds: How managers construe key organizational events. Academy of Management Journal, 33(1), 7-41.

Ivancevich, J. M., $\quad$ Konopaske, R., $\quad \&$ Matteson, M. T. 2014. Organizational behavior and management (10th ed.).

Jabbarian, J., \& Chegini, M. G. 2016. The effect of perceived organizational support on employee resistance to change: A study on Guilan municipal staff. Journal of History Culture and Art Research, 5(4). 
Jakarta Smart City. 2017, February. Membangun cashless society dengan sistem transaksi non tunai | Blog | Portal Jakarta smart city. Retrieved October 20, 2017, from http://smartcity.jakarta.go.id/blog/191/m embangun-cashless-society-dengansistem-transaksi-non-tunai

Jones, R. A., Jimmieson, N. L., \& Griffiths, A. 2005. The impact of organizational culture and reshaping capabilities on change implementation success: the mediating role of readiness for change. Journal of Management Studies, 42(2), 361-386.

Joniansyah. 2017, October 6. Ada Kartu E-Toll, Marga Mandalasakti Pastikan Tak PHK Karyawan - Bisnis Tempo.co. Retrieved October 20, 2017, from https://bisnis.tempo.co/read/1022672/ad a-kartu-e-toll-marga-mandalasaktipastikan-tak-phk-karyawan

Kaplan, M., \& Biçkes, D. M. 2013. The Relationship Between Psychological Capital and Job Satisfaction: A Study of Hotel Businesses in Nevşehir. Journal of Management \& Economics, 20(2).

Kerlinger, F. N., $\quad \& \quad$ Lee, H. B. 2000. Foundations of behavioral research(4th ed.). Fort Worth, TX: Harcourt College.

Kirrane, M., Lennon, M., O'Connor, C., \& $\mathrm{Fu}, \mathrm{N}$. 2016. Linking perceived management support with employees' readiness for change: the mediating role of psychological capital. Journal of Change Management.

Knowles, E. S., \& Linn, J. A. 2004. Resistance and persuasion. New York, NY: Routledge.

Kumar, R. 2005. Research metodology, a step by step guide for beginner. London, United Kingdom: Sage Publications.

Leonard, H. S., Lewis, R., Freedman, A. M., \& Passmore, J. 2013. The Wiley-Blackwell handbook of the psychology of leadership, change and organizational development. Malden, MA: WileyBlackwell.
Levene, R. A. 2015. Positive psychology at work: Psychological capital and thriving as pathways to employee engagement.

Lewis, S. 2011. Positive psychology at work: How positive leadership and appreciative inquiry create inspiring organization. Oxford: Willey-Blackwell.

Lizar, A. A., Mangundjaya, W. H., \& Rachmawan, A. 2015. The role of psychological capital and psychological empowerment on individual readiness for change. The Journal of Developing Areas, 49(5), 343-352.

Luthans, F. 2002. The need for and meaning of positive organizational behavior. Journal of organizational behavior, 23(6), 695706.

Luthans, F., Avey, J. B., \& Patera, J. L. 2008. Experimental Analysis of a Web-Based Training Intervention to Develop Positive Psychological Capital. Academy of Management Learning \& Education, 7(2), 209-221.

Luthans, F., Avey, J. B., Avolio, B. J., \& Peterson, S. J. 2010. The development and resulting performance impact of positive psychological capital. Human Resource Development Quarterly, 21, 41 $-67$.

Luthans, F., Avolio, B. J., Avey, J. B., \& Norman, S. M. 2007. Positive psychological capital: measurement and relationship with performance and satisfaction. Personnel

Psychology, 60(3), 541-572.

Luthans, F., Luthans, K. W., \& Luthans, B. C. 2004. Positive psychological capital: beyond human and social capital. Business Horizons, 47(1), 45-50.

Luthans, F., Youssef, C. M., \& Avolio, B. J. 2007. Psychological capital: Investing and developing positive organizational behavior. Positive

Organizational Behavior, 9-24.

Marketeers Editor. 2013, March 7. Studi kasus turn-around BUMN: PT Pos Indonesia. Retrieved November 7, 2017, from http://marketeers.com/studi-kasus-turnaround-bumn-pt-pos-indonesia/ 
Maddux, J. E. 2000. Self-efficacy: the power of believing you can. In C. R. Snyder, \& S. J. Lopez (Eds.), Handbook of positive psychology.

Meaney, M., \& Pung, C. 2008. Mckinsey global survey results: Creating organizational transformations. London: McKinsey \& Company.

Ming-Chu, Y., \& Meng-Hsiu, L. 2015. Unlocking the black box: Exploring the link between perceive organizational support and resistance to change. Asia Pacific Management Review, 20(3), 177183.

Nisfiannoor, M. 2009. Pendekatan Statistika Modern. Jakarta: Salemba Humanika

Noor, J. 2011. Metodologi penelitian: Skripsi, tesis, disertasi, dan karya ilmiah. Jakarta, Indonesia: Prenadamedia Group.

Nugraheni, A. L. 2012. Pelatihan self efficacy untuk meningkatkan kesiapan dalam menghadapi perubahan pada karyawan PT PLN (Persero) PUSDIKLAT (Unpublished master's thesis). Universitas Indonesia, Depok, Indonesia.

Oreg, S. 2003. Resistance to change: Developing an individual differences measure. Journal of Applied Psychology, 88(4), 680-693.

Prabowo, D. 2017, September 8. Transaksi nontunai juga diterapkan di tol JakartaTangerang - Kompas.com. Retrieved October 20, 2017, from http://properti.kompas.com/read/2017/0 9/08/204022121/transaksi-non-tunaijuga-diterapkan-di-tol-jakarta-tangerang

Ratnaningsih, I. Z., Prasetyo, A. R., \& Prihatsanti, U. 2016. Predicting innovative behavior among employees in a manufacturing company: the role of psychological capital. ANIMA Indonesian Psychological Journal, 31(2), 84-90.

Ratya, M. P. 2017, October 31. Jurus PT KAI melajukan perubahan perkeretaapian. Retrieved November 7, 2017, from https://finance.detik.com/beritaekonomi-bisnis/3708260/jurus-pt-kaimelajukan-perubahan-perkeretaapian
Rifqi, M. 2016. Pengaruh dimensi kepribadian emotional stability terhadap kesiapan karyawan untuk perubahan organisasi dengan empowering leadership sebagai variabel pemoderasi (Master's thesis, Universitas Gadjah Mada, Yogyakarta, Indonesia).

Robbins, S. P., \& Judge, A. T. 2013. Organizational behavior. Essex: Pearson Educated Limited.

Saksvik, I. B., \& Hetland, H. 2009. Exploring dispositional resistance to change. Journal of Leadership \& Organizational Studies, 16(2), 175-183.

Sapyaprapa, S., Tuicomepee, A., \& Watakakosol, R. 2013. Validation of psychological capital questionnaire in Thai employees. The Asian Conference on Psychology \& the Behavioral Sciences 2013 Official Conference Proceedings 2013, 394-399.

Stajkovic, A. D., \& Luthans, F. 1998. Selfefficacy and work-related performance: A meta-analysis. Psychological bulletin, 124(2), 240.

Sugiyono. 2007. Statistika untuk penelitian. Bandung: CV Alfabeta.

Sumintono, B dan Widhiarso, W. 2014. Aplikasi Model Rasch untuk Penelitian Ilmu-ilmu Sosial. Cimahi: Trim Komunikata Publishing House

Suwaryo, J., Daryanto, H. K., \& Maulana, A. 2015. Organizational culture change and its effect on change readiness through organizational commitment. Bisnis \& Birokrasi, 22(1), 68.

Tappin, R. M. 2014. Personality traits, the interaction effects of education, and employee readiness for organizational change: A quantitative study (10.13140/2.1.1978.4486)

(Master's thesis). Retrieved from ProQuest Dissertations and Theses database. (10.13140/2.1.1978.4486)

Vakola, M. 2014. What's in there for me? Individual readiness for change and the perceived impact of organizational change. Leadership \& Organization Development Journal, 35(3), 195-209 
Wanberg, C. R., \& Banas, J. T. 2000. Predictors and outcomes of openness to changes in a reorganizing workplace. Journal of applied psychology, 85(1), 132.

Windle, G. 2011. What is resilience? A review and concept analysis. Reviews in Clinical Gerontology, 21(2), 152-169 
